\title{
The Research of the Application of Pressure Teaching Method in Tennis Serving Teaching
}

\author{
Yuanhai Liu \\ Physical education department \\ Hubei University of Science and Technology \\ Xianning City, Hubei Province, China \\ e-mail:lyhai_2008@163.com \\ Gui Guan \\ Physical education department \\ Hubei University of Science and Technology \\ Xianning City, Hubei Province, China \\ e-mail:573386628@qq.com
}

\author{
Gang Yang \\ Physical education department \\ Hubei University of Science and Technology \\ Xianning City, Hubei Province, China \\ e-mail:568095926@qq.com \\ Milan Guo \\ Physical education department \\ Hubei University of Science and Technology \\ Xianning City, Hubei Province, China \\ e-mail: 693799757@qq.com
}

\begin{abstract}
On the basis of analyzing the influencing factors of tennis serving,we adopt research methods like literature ,questionnaire ,experimental and mathematical statistics and etc.to conduct a contrast experiment of pressure teaching method and traditional teaching method .The results from the study found that after the experiment the students in the experimental group is superior to the control group on stability and threat of tennis serving.The analysis shows that pressure teaching method can mobilize students' learning enthusiasm and ability of independent research, inspire their potential, build healthy personality,develop their intelligence and have a certain guiding significance on improving students ability of tennis,in addition,it can provide reference for tennis teaching in teaching methods.
\end{abstract}

Keywords-pressure teaching method; The tennis serving; The success rate

In today's world ,various tennis skills have developed for a long time, from which obvious omissions are hard to be found.Among numerous skills, serving is the only one that is free of the restriction of the opposite side ,and it is a skill which is complished by the server himself.Athletes in the tennis match can set different kinds of service according to his own tactics,it is the beginning of a point, and it is the beginning to attack the opponents.Especially in the first serving, athletes often use speedy and powerful serve to score directly, therefore, having good serving skills can master the initiative of the match victory.However, in the usual teaching, the tennis serving is basically limited by physical ability, technical knowledge and skills in every link, and we often neglect various pressure which is suffered by athletes in the specific competition environment.It leads to the result that the ordinary training level can't be well reflected in the tennis game greatly reducing the success rate and threat, especially it is prominently emerged in major sports events. Elliot and some other people ${ }^{[1]}$ have pointed out that serving is the most important action of tennis skills, but it is not easy to master.”A good serving is half of a winning game",'To serve successfully, and you will never fail in the game" these notions have become people's consensus.Therefore, apply pressure teaching method in the ordinary training to simulate all kinds of pressure that may be encountered in tennis games, to spur the athletes to improve the ability to cope with all kinds of pressure ,to adjust their mind and to temper their will in order to produce good teaching effect.All of the above has the vital significance to improve students' serving ability, and in teaching method it can provide reference and lessons for tennis teaching at the same time.

\section{THE RESEARCH OBJECTS AND METHODS}

\section{A. The research objects}

This research chooses students from grade 2 social sports tennis major classes as the research object,the 12 boys from class 1 as experimental group and 11 boys from class 2 as the control group.

\section{B. Research Methods}

This research mainly adopts literature data method, questionnaire survey method, experimental method and logical analysis,etc.

\section{THE RESULTS AND ANALYSIS}

\section{A. Related influencing factors in tennis serving}

Tennis serving is the only shotting method that held by yourself and it is not controlled by the opposite side. It is the powerful weapon for the excellent tennis athletes to win the game.Serving is the beginning of every score as well as the offensive, and it is the start of two sides' attack-defense at the same time ${ }^{[2]}$.From analysis of the world's top tennis game's tactics, when it comes to a specific tennis game,if the sever scores ,we often call it"serving out smoothly" 
while the receiver scores we call it”breaking successfully".From the connotation of diction, we can see that people take the server scoring for granted while the receiver scoring is not that easy.

Thus, the server is taking the initiative and has a big advantage over the opposite side. And look at the rules of tennis, of all the ball games tennis is only one that allows players to serving out the ball twice. In spite of this, the world's top players also often appear double faulting in the game, so it is rather difficult to serving with stability threat in actual combat of tennis.

It is exactly that the tennis serving plays an important role, and is difficult to master, so the related factors that influence serving drawing common attention from the researchers.As Xin $\mathrm{Xu}^{[3]}$ (2005) analyzed the technical types of tennis serving and major technical factors, and puts forward four kinds of practice methods:practice of throwing the ball, simulation exercises, wave slapping fixed hanging ball, throwing the ball cooperating with hitting the ball. Xu pointed out that serving training needs to pay attention to the accuracy of placement ,thus to improve the lasting stability of the serving and accelerate the ball's flying speed and strengthen the persistent antagonism of the serving; Yu Peng ${ }^{[4]}(2010)$ proposed the tennis athlete's physical quality level, degree of skills and tactics in training, coach's ability and attitude, interference from outside of the game, mental state etc. are all the influence factors of the tennis serve, but physical quality and the skills and tactics of the athletes affect the results directly, especially the moving speed, strength quality, etc.Xiping $\operatorname{Ren}^{[5]}$ (2012) argued that placement, rotation and speed are important symbols of effect of the tennis serve,instantaneous angle as the ball leaving the racket, height of the shotting moment,the initial velocity when hitting the ball, the flying trajectory of the ball and the flying time are all important technical indexes influencing the effect of serving. Ren also started from the objective laws and technical principle of serving to modify and improve the effect of the serve.

In order to have a further understanding and analyze the influencing factors of tennis serving correctly, on the basis of collating the predecessors' related research results and interviewing some experts, we compile a questionnaire containing the coordination of serve, leg strength, shotting point, arm strength,throwing the ball and the strength of waist and abdomen, a total of six items of a semi-overt questionnaire,and hand out to 50 tennis experts, scholars, asking them to give corresponding score according to the close degree, five of which is very close, 4 for close, 3 for general, 2 is not very close, one is very close.

This questionnaire adopted the method of immediate delivery and immediate recovery face to face. Its recovery rate was $100 \%$, and 45 copies of all the questionnaires are effective, of which the effective rate was $90 \%$. Statistical results are showed as table 1, the top three factors in turn are: leg strength , arm strength and coordination of serve ,which can be considered to be the main factors influencing the serving technical level.

TABLE1 STATISTICAL TABLE ABOUT RESEARCH OF SERVE'S INFLUENCING FACTORS $(\mathrm{N}=45)$

\begin{tabular}{lcc}
\hline Influencing factors & Average score & Ranking of influence degree \\
\hline Throwingthe ball & 3.8889 & 5 \\
Cooperation & 4.0926 & 3 \\
Shotting point & 3.9259 & 4 \\
Arm strength & 4.1597 & 2 \\
Strength of twist and abdomen & 3.1852 & 6 \\
Leg strength & 4.3889 & 1 \\
\hline
\end{tabular}

B. Difference examination before the experiment

Before the experiments we test the serving ability of the research objects , of which the main evaluation index the success rate of serving. In order to test the quality of service, we respectively test the success rate with the pursuit of speed, the pursuit of serving angle ,and the pursuit of both speed and angle.Test method: every student serves four groups of the ball, each group contain 10 goals on the left court and 10 on the right court. The second group serves require that the first placement must be in the limited zone (inside, in the middle of ,outside of the 1 square meter's square)The third group to requires the first placement must be in the serve court, and the second placement must be two meters or more after the end line;The fourth group requires the ball to fall in the restricted zone (inside, in the middle of ,outside the 1 square meter's square), and the ball's second placement must be two meters or or more outside the end line.Missed serve scores 0 and the students should serve again if hitting the net. Statistical result of the test is showed as table 2 and it indicates that there is no significant difference between the experimental group and control group in serving ability $(\mathrm{P}>0.05)$. 
TABLE2 STATISTICAL TABLE OF TEST BEFORE EXPERIMENTS( $\mathrm{N}=23$ )

\begin{tabular}{lcccc}
\hline Test index & average scores of experimental group & average scores of control group & $t$ & $p$ \\
\hline Group 1 & $6.6667 \pm 1.6330$ & $6.2500 \pm 0.8864$ & 0.616 & 0.074 \\
Group 2 & $4.6667 \pm 0.8165$ & $4.6250 \pm 1.0606$ & 0.080 & 0.407 \\
Group 3 & $5.1667 \pm 1.1691$ & $4.5000 \pm 0.9258$ & 0.194 & 0.647 \\
Group 4 & $2.8333 \pm 0.9832$ & $3.0000 \pm 0.9258$ & 0.325 & 0.723 \\
\hline
\end{tabular}

In order to avoid the impact of the internal validity of the results of the experiment, according to the survey above, we found that the serving ability is also closely related to physical coordination, leg strength and arm strength. Three indicators like shuttle running, tennis trowing away and rope skipping are added to be measured before the experiment. Shuttle running in a fan: this sport event including physical qualities such as speed, leg strength, endurance, explosive force and etc.. Test time in the experiments is record as the

experimental data.Tennis throwing away: this exercise can checkout leaving speed of the ball effectively, so it is tested to measure the arm strength, through testing the destination of the ball as test index and as the experimental data. Rope skipping: this sport event can checkout the personal reactions effectively, endurance and coordination of exercise, this experiments counts the number of skipping per minute as test index and record number of skipping as the experimental data.

TABLE 3: DATA STATISTICS OF RELATED QUALITIES OF TEST $\quad(\mathrm{N}=23)$

\begin{tabular}{lcccc}
\hline Test index & average scores of experimental group & average scores of control group & $t$ & $p$ \\
\hline Shuttle running & $18.9000 \pm 1.5950$ & $18.5500 \pm 2.0030$ & -0.419 & 0.566 \\
Tennis throwingaway & $42.3333 \pm 5.6095$ & $44.4850 \pm 3.8707$ & 1.007 & 0.680 \\
Rope skipping & $83.0000 \pm 5.2153$ & $80.0000 \pm 4.7208$ & 1.126 & 1.000
\end{tabular}

Tests of the above are all conducted for three times and take the value of ultimate data to be dealt with the Microsoft ware SPSS17.0, using independent sample for $\mathrm{T}$ test and the results show that there was no significant difference in all of the above tests $(p>0.05)$, therefore, two groups of students had no significant difference about the related service qualities, in addition, two groups of students major in the same profession, follows the same teaching programme and the consistent training goals, thus they can be regarded as the mainly equal teaching factors that does not have distinction and they belong to the same level,so they can be regarded as equal experimental objects.

\section{Teaching process of the experiment}

This teaching experiment chooses the base line driving with both forehand and backhand as the main teaching content,from October 15, 2012 to December 14, 2012, a total of 36 class hours in 9 weeks.we elaborate pressure teaching experiment scheme for the experimental group according to the characteristics of the tennis skills and tactics , combining with the root causes of stress and simulation solution, Aiming at the source of pressure, design pressure,we design a pressure teaching scheme to simulate various pressure of competition, pressure are respectively designed as the following four aspects:the first is the external environment and the application of tennis skills and tactics such as sunlight, dust, court, etc.; the second is the abnormal behavior of the opponent that can lead to changes of mind and attention, such as shouting, toughness, tenaciousness, etc.; the third is the mood swings generated by unequal referee decisions; the fourth is stress that causes by oneself, such as the score takes the lead or lags behind, fatigue or pain, will be rewarded or punished,etc.,and the control group apply traditional teaching methods.

In addition, in order to eliminate the irrelevant variable which can influence the experimental results and ensure that the experimental group and control group of students have the consistent basis,and are equal in the teaching content, teaching hours, teaching court and equipments, exercise capacity ,we provide students with the same study materials and the teaching is strictly accordant with the requirements of the class in the process of experiment, all the teaching content must be complished within the teaching time, and banned two groups of students from doing related exercise to eliminate the influence of the irrelevant variables.

\section{Analysis of experiments results}

After 9 weeks'teaching experiments, we tested the serving ability of the experimental group and the control group (methods are the same with the test before this experiment),here are the test results(table 4).P $<0.05$ came out in the first, the second and the fourth group, which indicates that the experimental group and the control group have significant difference in the above three groups' serving, 
according to the table above, the results of the experimental group was better than the control group; $\mathrm{P}>0.05$ came out only in the third group and it had no significant difference between the experimental group and the control group.Thus it can be seen that the experiment group and the control group have significant difference in terms of the tennis serve ability after the experiment. It concludes that the pressure teaching method helps students with the application of tennis serve ability to some degree, and it can promote the students to grasp one of the basic tennis skills better,in addition,it can help improve the students' self-confidence of technical exercise effectively and help students concentrate their attention and correct students' attitude of learning tennis, what's more, it can promote the students' enthusiasm of learning tennis thus to promote the effect of students' tennis learning more effectively.

TABle 4: DATA Statistics OF THE TEST AFTER THE EXPERIMENT $(\mathrm{N}=23)$

\begin{tabular}{lcccc}
\hline Test index & average scores of experimental group & average scores of control group & $t$ & $p$ \\
\hline Group 1 & $13.6667 \pm 2.1603$ & $9.0000 \pm 0.7559$ & 0.952 & 0.026 \\
Group 2 & $9.5000 \pm 0.7638$ & $5.2370 \pm 0.7560$ & 0.608 & 0.022 \\
Group 3 & $9.1667 \pm 1.1691$ & $6.8750 \pm 0.8345$ & 0.045 & 0.442 \\
Group 4 & $6.0000 \pm 1.6733$ & $4.01920 \pm 0.7560$ & 0.047 & 0.039 \\
\hline
\end{tabular}

Analysis of the above indicates that the stress teaching method can not only help students learn basic skills of tennis firmly, it can also help enhance the student's own anti-pressure ability greatly at the same time, and the students can still maintain a better state of serving and a higher level of serving at a crucial moment so that not to cause big failure finally under the excessive tension .Through the pressure teaching method, the students try to overcome all kinds of pressure of the environment, so they can largely exert their advantages and the positive side of their own and ultimately apply this ability to tennis game.It shows that students can adjust themselves actively under the environment of all kinds pressure. After a long-term training of pressure teaching, students will be more mature in dealing with crucial game,the key set of the game and key scores, thus it will slowly accumulate their self-confidence and exert their own subjective dynamics and cultivate their interest in learning. While the conventional common teaching methods, of which the teaching pattern is unitary and during the teaching process the students just do imitative practice under the teacher's demonstration and explanation without the practicing the psychological aspect , causing the consequences that in the game, the more crucial the game is, the more likely it is to error. Therefore,the pressure teaching method has a more specific and more effective advantage over the conventional one it can improve the teaching effect significantly .

\section{THE CONCLUSIONS AND RECOMMENDATIONS}

\section{A. The conclusions}

a)Applying the pressure teaching method can help the students form the correct dynamic stereotype, improve the success rate of serving, promote the quality of teaching.It can also help solve the "soon learn, soon forgotten" of students of different basis.

b)Applying the pressure teaching method can make students have a strong psychological regulation ability, temper quality of will, exert their subjective dynamics,play their technical levels steadily.

\section{B. Recommendations}

a) The principle of "step by step" should be followed in the process of the serving training, first of all, it should be mainly based on basic actions and enhancing the stability of serving and increasing the rate of goals; After being familiar with the action skills and mastering them, then add power and rotating, asking for a better placement and gradually increase the threatening of serving.

b)When applying the pressure teaching method, the teachers should often communicate with the students to learn more information about the quantity and intensity of their exercise, especially learn the psychological level of the students, in order to help them adjust all kinds of pressure from the environment, prompting students to have good psychological regulation ability under proper simulated stress environment , thus to cope with a variety of mutations in the external environment.

\section{THANKS}

In this paper as national entrepreneurship training project"xianning amateur tennis training base"(project number:201210927085) one of the initial results.

Author: $\quad$ Yuanhai $\quad$ Liu(1980-),male,from Xiaogan ,Hubei, master, instructor, research direction is physical education and training.Tel:13971827866.Address:Xianning Road at Num.88 of Spring, Xianning, Hubei ,at center campus of Xianning Science and Technology University.

\section{REFERENCES}

[1]Elliot B C, Marsh T, Blanksby B. A three-dimensional cinematographic analysis of the tennis serving [J]. International Journal of Sports Biome-chanics, 1986, 
2(4) : 260-271.

[2]Zhixiang Tao,Bing Qi and etc..Research of the tennis serve system[J].Journal of Beijing Sport University,2004(12):1695-1697.

[3]Xin Xu.Discussion about technical training of tennis serving[J].Journal of Nanjing Institute of Physical Education (Natural Science),2005(12):66-68.
[4]Peng Yu.Analysis of Influence Factors About Tennis Serving[J].Journal of Jingmen Technical College , 2010(2):78-80.

[5]Xiping Ren.Mechanics analysis of influencing factors about tennis serving[J].Journal of Zhejiang Normal University (Natural Sciences) 2012 (5): 226-230. 